\title{
First record of the Mourning Gecko, Lepidodactylus lugubris (Duméril \& Bi- bron), from the Turks and Caicos Islands with additional observations from the Bahamas
}

\author{
Brandon M. Ruhe ${ }^{1 *}$ and Amy R. Ruhe ${ }^{2}$ \\ 'The Mid-Atlantic Center for Herpetology and Conservation, P.O. Box 620, Oley, PA 19547, USA. \\ ${ }^{2}$ National Park Service, Valley Forge National Historical Park and Hopewell Furnace National Historic Site, 1400 North Outer Line Dr., King of \\ Prussia, PA 19406, USA. \\ *Corresponding author (bruhe@machac.org)
}

Date of publication: 14 March 2019.

Citation: Ruhe BM, Ruhe AR (2019). First record of the Mourning Gecko, Lepidodactylus lugubris (Duméril \& Bibron), from the Turks and Caicos Islands with additional observations from the Bahamas. Caribbean Herpetology, 66, 1-3.

DOI: $10.31611 /$ ch.66

The Mourning Gecko, Lepidodactylus lugubris, while native to coastal areas and islands within the Pacific and Indian Oceans, has spread to tropical and sub-tropical portions of the world via human activities such as transoceanic shipping. Henderson et al. (1976) noted the first Atlantic Basin record in the Western Hemisphere, in Nicaragua. Lorvelec et al. $(2011$, 2017) summarized observations in the Western Hemisphere with the addition of new records from locations on Guadeloupe. Krysko \& MacKenzie-Krysko (2016) reported additional records from North Bimini in the Bahamas and Bosch \& Paez (2017) noted the species' presence in Cuba. Herein, we report the first record of L. lugubris from the Turks and Caicos Islands and two additional locations in the Bahamas situated $\sim 210 \mathrm{~km}$ ESE and $234 \mathrm{~km}$ SE of the location reported by Krysko \& MacKenzie-Krysko (2016). We believe that our new records of L. lugubris are clone type A based on external morphology (Yamashiro et al. 2000; Hoogmoed \& Avila-Pires 2015; Ineich 2015; Griffing et al. 2018) and that is consistent with individuals reported from nearby locations (Krysko \& MacKenzie-Krysko 2016; Bosch \& Paez 2017).

On 16 October 2015 we encountered two Lepidodactylus lugubris under a pile of boards and plastic adjacent to Bourreria ovata and Metopium toxiferum clumps near Sapodilla Bay, Providenciales, Turks and Caicos Islands (21.74089, -72.28417) (Fig. 1A; East Stroudsburg University of Pennsylvania photo voucher ESUP R00231). This observation marks the first record for the Turks and Caicos Islands and the second observation in the Lucayan Archipelago. The location is only $\sim 250 \mathrm{~m}$ WNW of South Dock, a core municipal seaport for the Turks \& Caicos Islands. As transoceanic shipping appears to be one of the main modes of introduction for the species, the proximity to the port is unsurprising. Hemidactylus mabouia co-occurred with L. lugubris at the observation point. We did not observe L. lugubris in other portions of Providenciales, North Caicos, or Middle Caicos, although we did not make an exhaustive search for the species. We frequently observed $H$. mabouia throughout Providenciales, North Caicos, and Middle Caicos.

On 1 February 2018 we encountered a single juvenile L. lugubris (Clone A) under a board 350 m SSW of Black Point dock, Black Point District, Great Guana Cay, Exuma Islands, Bahamas (24.09570, -76.40261) (ESUP R00232, photo voucher). This observation marks the second record for the Bahamas, an extension of $\sim 344 \mathrm{~km} \mathrm{SE}$ of the Krysko \& MacKenzie-Krysko (2016) observation in North Bimini, Bahamas. On 3 February 2018, we encountered seven adult $L$. lugubris (Clone A) in association with boards, a pallet, and other flotsam wedged against a shrub clump in a small sea-side park on Paradise Island, New Providence, Bahamas (25.081811, -77.32931) (Fig. 1B; photo voucher ESUP R00231). Two of the seven adults were found under a small clump of wet plastic lodged in the crotch of a mature Coccoloba uvifera. Hemidactylus mabouia co-occurred with L. lugubris at the observation point. This record is the third observation in the Bahamas, $>144 \mathrm{~km} \mathrm{NW}$ of the Black Point District observation (above), and $>210$ km ESE of the Krysko \& MacKenzie-Krysko (2016) observation in North Bimini, Bahamas. The 
observation point is located across a narrow channel from Nassau (New Providence Island) Port, one of the busiest ports in the West Indies.

The documentation of L. lugubris on several widely distributed islands suggests that the species may be present throughout developed areas in the Bahamas. The Paradise Island observation point is situated $<0.5 \mathrm{~km}$ from Nassau, New Providence Island, and presumably the species is also found on that island. Bridges and substantial boat traffic connect islands in the Bahamas, and Nassau may have been the point of introduction for L. lugubris on Paradise Island, although we did not conduct searches on New Providence Island for L. lugubris.

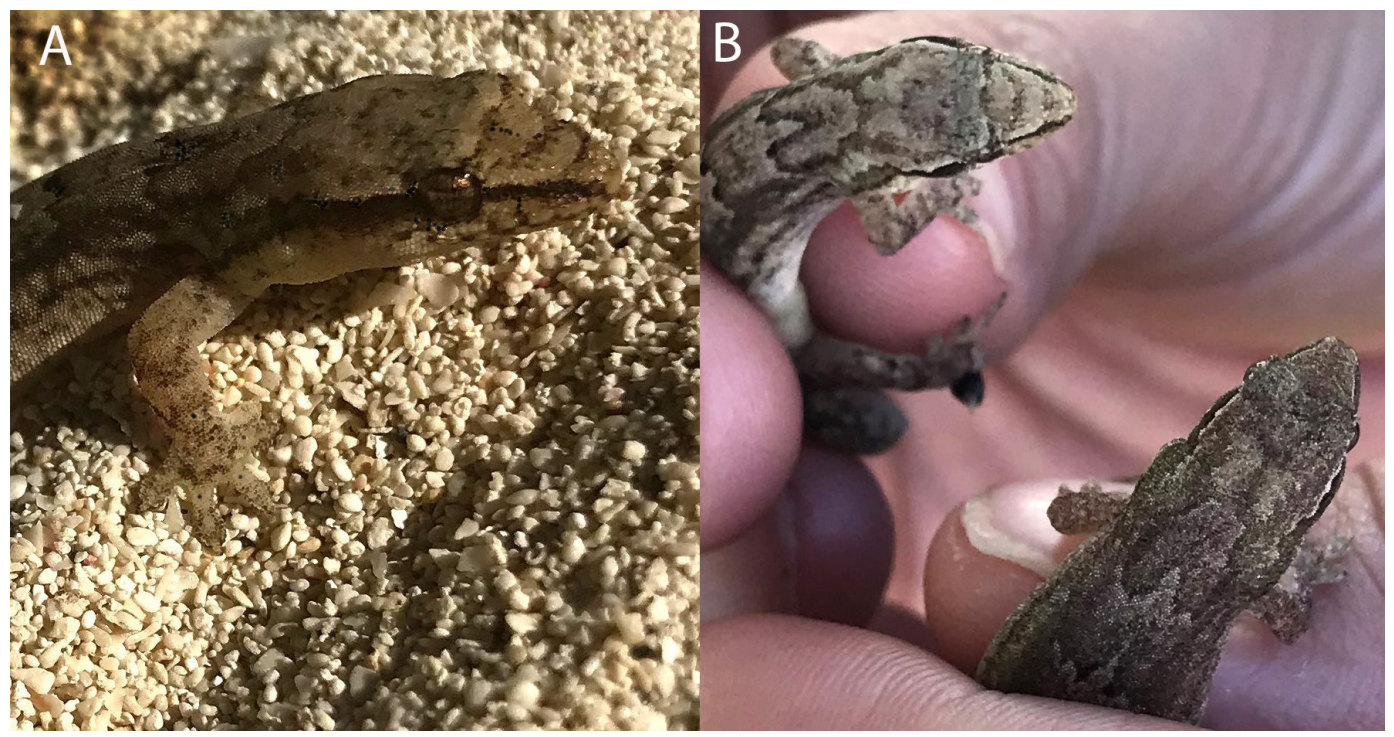

Figure 1. Adult mourning geckos (Lepidodactylus lugubris) from (A) Providenciales, Turks and Caicos Islands and (B) Paradise Island, Bahamas.

\section{Acknowledgments}

We thank Edward and Susan Croushore, Thomas C. LaDuke of East Stroudsburg University of Pennsylvania for voucher verification and record processing, Ava M. Ruhe, Ethan H. Ruhe, and Edward D. Croushore for field assistance, and R. Graham Reynolds and S. Blair Hedges for their constructive comments. The authors assert that the views expressed in this paper do not necessarily represent the views of the Department of the Interior or the United States Government.

\section{References}

Bosch RA, Páez RB (2017) First record from Cuba of the introduced mourning gecko, Lepidodactylus lugubris (Duméril and Bibron, 1836). Biolnvasions Records, 6, 297-300.

Griffing AH, Sanger TJ, Matamoros IC, Nielsen SV, Gamble T (2018) Protocols for husbandry and embryo collection of a parthenogenetic gecko, Lepidodactylus lugubris (Squamata: Gekkonidae). Herpetological Review, 49, 230-235.

Henderson RW, Villa J, Dixon JR (1976) Lepidodactylus lugubris (Reptilia: Gekkonidae) A recent addition to the herpetofauna of Nicaragua. Herpetological Review, 7, 173.

Hoogmoed MS, Avila-Pires TCS (2015) Lepidodactylus lugubris (Duméril \& Bibron 1836) (Reptilia: Gekkonidae), an introduced lizard new for Brazil, with remarks on and correction of its distribution in the New World. Zootaxa, 4000, 90-110.

Ineich I (2015) New data about the triploid clone C of the unisexual-bisexual Lepidodactylus lugubris (Duméril \& Bibron, 1836) complex (Gekkonidae). Herpetology Notes, 8, 165-168. 
Krysko KL, MacKenzie-Krysko C (2016) First report of the Mourning Gecko, Lepidodactylus lugubris (Duméril \& Bibron 1836), from The Bahamas. Caribbean Herpetology, 54, 1-2.

Lorvelec O, Levesque A, Bauer AM (2011) First record of the Mourning Gecko (Lepidodactylus lugubris) on Guadeloupe, French West Indies. Herpetology Notes, 4, 291-294.

Lorvelec O, Barré N, Bauer AM (2017) The status of the introduced Mourning Gecko (Lepidodactylus lugubris) in Guadeloupe (French Antilles) and the high probability of introduction of other species with the same pattern of distribution. Caribbean Herpetology, 57, 1-7.

Yamashiro S, Toda M, Hidetoshi O (2000) Clonal composition of the parthenogenetic gecko, Lepidodactylus lugubris, at the northernmost extremity of Its range. Zoological Science, 17, 1013-1020. 